\title{
Documenting, organizing and demonstrating the cartographic wealth of a library, through an information system, to the public
}

\author{
Angeliki Tsorlini ${ }^{\mathrm{a}, *}$ \\ ${ }^{a}$ Laboratory of Cartography and Geographical Analysis - CartoGeoLab, School of Rural and Surveying Engineering, Aristotle \\ University of Thessaloniki, Greece, atsorlin@topo.auth.gr \\ * Corresponding author
}

Keywords: historical maps, cartographic heritage, digital map libraries, digital technologies, digital humanities

\begin{abstract}
:
Historical maps consist an important source of information and a research tool for several researchers of various scientific fields, especially the humanities (Michev 2016), who are working on the geographic analysis of the environment. For them, the digital comparative analysis of historical and modern maps offers a variety of benefits. It expands the scope of their research, providing them the opportunity to study the geometric and thematic properties of the maps, or they use maps constructed on different periods to detect and determine changes in the physical environment, border changes, or changes on the toponyms (e.g. Boutoura \& Livieratos, 1986, 2006; Livieratos, 2006; Tsorlini et al, 2010). This is really essential, especially when these changes are only apparent through maps and no other written source exists (Tsorlini et al, 2017).
\end{abstract}

Historical maps in different forms, independent or embedded in books, atlases or map series, are located in map collections mainly in libraries worldwide. These cartographic materials abroad are stored in specific departments in the libraries, where specialized personnel deals with them and is responsible for their management, preservation and demonstration to the public. This is not the case for our country, since many historical maps and other related cartographic material in libraries, remain almost unknown to researchers and generally to the public. Sometimes, there are difficulties even to detect historical maps in the library's system, because they are documented and recorded following specific rules related mainly to traditional descriptive methods applied in book-keeping and book-archiving (Boutoura, 2014). As a consequence, there are important maps, who haven't been studied or analysed until today and their important value has not been exploited yet in library's environment.

One of the most important libraries in Greece and the second in size after the National Library, is the Library and Information Centre of the Aristotle University of Thessaloniki (AUTH Library). The cartographic material located in AUTH Library has not been documented and studied properly in all its size and the cartographic wealth has not been exploited in Library's environment, until its cooperation with the Laboratory of Cartography and Geographical Analysis which was realized recently. In the frame of this cooperation, a research project was developed focusing on one of the AUTH Library's collections, the very important Ioannis Tricoglou Library, with the aim to collect, document and organize the cartographic material found in this collection, in an information system, which will give the opportunity to researchers and to the general public to search for maps, independent or embedded in books, and to find relevant information for them through an easy and user-friendly digital environment. In this way, historical maps and other cartographic material located in Library's collections will be demonstrated to researchers and the general public, presenting and promoting also the cartographic wealth of the library.

The main stages of this project are: a) the collection and documentation of the maps found in Ioannis Tricoglou Library, b) the proper transformation of these data to provide information through a database, c) the connection of the maps in the database with other related textual and pictorial sources, in order to enrich the information provided for the maps not only for researchers and students, but also for the library's staff, simplifying in this way the searching procedure and finally (Tsorlini et al, 2018a), and finally, d) the development of a user-friendly digital environment, which will provide access to historical maps and relevant cartographic material located in Ioannis Tricoglou Library. Emphasis on this project is given to the maps which were found inside the books, since they were not recorded and documented correctly, they were not digitized in the proper way, thus it was impossible to detect them through the existing library's system (Tsorlini et al, 2018b).

In this paper, we will analyse shortly the main stages of the project and we will discuss the problems appeared during the whole procedure. Moreover, we will present its results, which can assist to the improvement of the library's searching system and to the demonstration of the unknown cartographic wealth of the library to the academic community and general public. 
The research project was granted by the State Scholarships Foundation of Greece (IKY), funded by the programme "Strengthening Post-Academic Researchers" from the resources of the Operational Program "Human Resource Development, Education and Lifelong Learning”, priority Axes 6,8,9. The programme is also co-funded by the European Social Fund (ESF) and the Greek Government.

\section{References:}

Boutoura C., E. Livieratos, 2006. 'Some fundamentals for the study of the geometry of early maps by comparative methods'. e-Perimetron, 1, (1): 60-70, ISSN 1790-3769,

[http://www.e-perimetron.org/Vol_1_1/Boutoura_Livieratos/1_1_Boutoura_Livieratos.pdf].

Boutoura C., E. Livieratos, 1986. 'Strain analysis for geometric comparisons of maps’. The Cartographic Journal, 23:2734, [http://www.ingentaconnect.com/content/maney/caj/1986/00000023/00000001/art00002].

Boutoura C., 2014. 'The course of Danube in some representative 18th century maps as given online in textual and image structures by a leading web provider of digital maps'. In Proceedings of 9th ICA-Commission Conference on Digital Approaches to Cartographic Heritage, Budapest, Hungary, 4-5 September.

Livieratos E., 2006. 'On the study of the geometric properties of historical cartographic representations'. Cartographica, 41 (2): 165-175, [http://utpjournals.metapress.com/content/ rm863872894261p4/].

Michev B. 2016. 'Map exhibits as an important tool for connecting Cartography and the Digital Humanities'. In Proceedings of the 11th International Workshop on Digital Approaches to Cartographic Heritage, ICA-Commission on Cartographic Heritage into the Digital, Riga, Latvia. ISSN 2459-3893.

Tsorlini A., C. Boutoura, E. Livieratos, 2018a. 'Connecting maps embedded with textual sources in a digital library environment'. In Proceedings of $15^{\text {th }}$ National Cartographic Conference of the Hellenic Cartographic Society “Cartography of Crises”, ISBN 978-960-88380-8-6, pp. 292-301. Thessaloniki: Hellenic Cartographic Society. [In Greek]

Tsorlini A., C. Boutoura, A. Nasta, E. Livieratos, 2018b. 'Searching for maps embedded in books in digital libraries environment'. In Proceedings of the 13th International Workshop on Digital Approaches to Cartographic Heritage, ICACommission on Cartographic Heritage into the Digital, Madrid, Spain. ISSN 2459-3893, pp.107-116.

Tsorlini A., R. Sieber, L. Hurni, 2017. 'Combining current vector data with historical textual data and data extracted from old maps to study the development of the city of Zurich, Switzerland'. In Proceedings of 12th Commission Conference on Digital Approaches to Cartographic Heritage, Venice, Italy. ISSN 2459-3893, pp. 29-39.

Tsorlini A., M. Daniil, M. Myridis, C. Boutoura, 2010. 'An example of studying the evolution of a local geographic milieu in early 20th century Greece: Generalkarte (1900-1904) vs National mapping (1917) representations’. In Proceedings of the 5th International Workshop Digital Approaches to Cartographic Heritage, Vienna, Austria. 